\title{
Myelomatosis: Comparison of Melphalan and Cyclophosphamide Therapy
}

British Medical fournal, 1971, 1, 640-641

\section{Summary}

Untreated patients suffering from myelomatosis were allocated at random for treatment by the daily oral administration of either cyclophosphamide or melphalan: 141 received cyclophosphamide and 133 melphalan. The trial began on 1 October 1964 and the intake of patients continued until 31 July 1968. The statistical analysis includes follow-up of the surviving patients to 31 May 1970.

The most important single factor affecting the prognosis was the blood urea concentration at presentation. The median survival of the 125 patients whose blood urea concentration was less than $40 \mathrm{mg} / 100 \mathrm{ml}$ was 33 months, compared with 20 months for the 96 patients whose blood urea concentration was $40-79 \mathrm{mg} / 100 \mathrm{ml}$ and two months for the 55 patients whose blood urea concentration was $80 \mathrm{mg} / 100 \mathrm{ml}$ or more.

The median survival periods of the 114 patients in the cyclophosphamide group and of the 105 in the melphalan group whose blood urea concentration at presentation was less than $80 \mathrm{mg} / 100 \mathrm{ml}$ were 27 and 23 months respectively. The difference is not statistically significant.

\section{Introduction}

Reports on the treatment of myelomatosis with cyclophosphamide (Cytoxan, Endoxana) and with sarcolysin first appeared in 1958. Sarcolysin is the racemic form of phenylalanine nitrogen mustard and it has been largely replaced by the laevo-isomer, melphalan (Alkeran). At the time of starting the present co-operative trial no randomized comparison of cyclophosphamide and melphalan in the treatment of myelomatosis had been reported, nor, indeed, has a long-term study of this kind yet been described. The relevant literature on cyclophosphamide and melphalan in myelomatosis will be summarized in a detailed report to the Medical Research Council; since they were introduced the median survival from the time of diagnosis of patients with myelomatosis has increased from about 10 to about 24 months. No evidence was available to suggest that one of these drugs was superior to the other and the Working Party therefore decided to compare them in a large series of patients. During the course of the trial a report was published by Galton and Peto (1968). This short report on the completed trial is restricted to the effects of treatment on survival.

\section{Present Trial}

The present trial, in which the two drugs were directly compared, was begun in October 1964, and the intake of patients continued until August 1968, when 292 cases had been

Medical Research Council, London W1N 4AL

Report of the Medical Research Council's Working Party for Therapeutic Trials in Leukaemia

The members of the Working Party over the period of the trial were: Professor L. I. Witts (chairman), Dr. E. K. Blackburn, Dr. S. T. Callender, Professor J. V. Dacie, Professor W. M. Davidson, Professor Richard Doll, Dr. E. C. Easson, Dr. J. R. Fountain, Professor R. M. Hardisty, Professor Fr. J. G. Havhoe, Dr. C. A. Holman, Professor A. Jacobs, Mr. R. Peto, D. J. G. H. Pike, Dr. L. S. Sacker, Sir Ronald Bodley Scott, Dr. R. B. Thompson, Professor G. Wetherley-Mein, and Dr. D. A. G. Galton (secretary). notified, of which 276 (141 males) satisfied the requirements for entry. Patients were eligible for admission to the trial only if $(a)$ they had not received previous chemotherapy and (b) they had at least two of the following: (1) abnormal plasma cells in the bone marrow, (2) positive radiological findings of myelomatosis $x_{x}$ and (3) a monoclonal immunoglobulin in the serum, the urine, or both. Palliative local $x$-irradiation or steroid therapy for the hypercalcaemia did not preclude entry. Both drugs were administered continuously except for intermissions to permit the recovery of the neutrophil and platelet counts if these became depressed. The initial daily oral dose of melphalan was $4 \mathrm{mg}$ and of cyclophosphamide 150 mg. Appropriate reductions were made for uraemic patients and after the first 10 days the dose was reduced according to the trend in the blood counts.

Until January 1967 melphalan was available only in 2-mg tablets. To permit small adjustments of dosage comparable to that possible for cyclophosphamide (available in $50-\mathrm{mg}$ and 10 -mg tablets), a batch of tablets each containing $0.25 \mathrm{mg}$ of melphalan was prepared and these were used from 24 January 1967. No rules were laid down about the use of phosphates, sodium fluoride, or anabolic steroids, and local $x$-irradiation for the relief of pain was allowed.

The patients were allocated randomly as described in previous reports (Medical Research Council, 1963, 1968) for treatment with melphalan or cyclophosphamide. Observations were reconded until 31 May 1970, when 212 patients had died; the minimum possible follow-up was 22 months and the maximum five years and eight months. No patients were lost to follow-up. Of the 276 patients $141(51 \%)$ were allocated to the cyclophosphamide schedule (64 males) and $133(48 \%)$ were allocated to the melphalan schedule ( 77 males). One investigator agreed to include a control group of patients who would receive no chemotherapy, but only two patients were entered.

\section{Results}

The median survival for all patients was 18 months, and the estimated four-year survival is $20 \%$ (Fig. 1). When the survival figures were analysed it was found that the blood urea concentration and the serum albumin concentration at presentation were the most important features influencing the prognosis, and that their effects were largely independent of each other. The higher the blood urea concentration or the lower. the serum albumin concentration, the worse was the prognosis. Fig. 2 shows the relation between survival and the blood urea concentration at presentation. The survival times of the 125 patients whose blood urea concentration at presentation was less than $40 \mathrm{mg} / 100 \mathrm{ml}$ are shown in curve $A$, those of the 96 patients with concentrations from 40 to 79 $\mathrm{mg} / 100 \mathrm{ml}$ in curve $\mathrm{B}$, and those of the 55 with concentrations of $80 \mathrm{mg} / 100 \mathrm{ml}$ ar more in curve $C$. The median survival for the patients shown in curve $A$ was 33 months, for those in curve B 20 months, and for those in curve $\mathrm{C}$ two months.

In comparing the effect of the two treatments on survival we have considered only the patients whose blood urea con- 8 centration was below $80 \mathrm{mg} / 100 \mathrm{ml}(114$ of the $141(81 \%)$ patients treated with cyclophosphamide and 105 of the 1338 $(78 \%)$ treated with melphalan). The survival curves of these two groups are shown in Fig. 3. The median survivals did not differ significantly, being about two years in each treat- $\stackrel{?}{?}$ ment group. The estimated proportions surviving four years or more were $25 \%$ in both groups.

In the course of the trial 5 of the 212 patients (2\%) who 
died were severely neutropenic and/or thrombocytopenic at the time of death. All five had received continuous melphalan therapy: two were in advanced renal failure when the treatment was started, and two had a rapidly increasing blood urea concentration during the course of their treatment. The fifth patient had no evidence of renal failure and the terminal rapid fall in the neutrophil and platelet counts could not have been predicted from the trends in the counts during the preceding month.

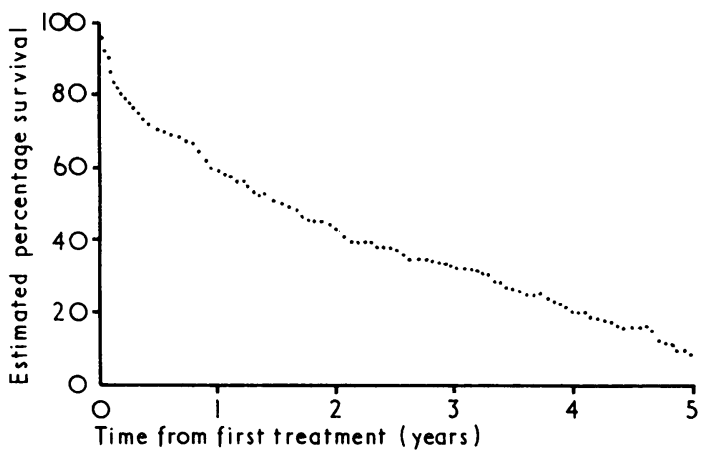

FIG. 1-Estimated percentage survival from the start of treatment of $\mathbf{2 7 6}$ patients suffering from myelomatosis admitted to the trial from 1 October 1964 to 31 July 1968 and followed until death or 31 May 1970. The median survival was 18 months.

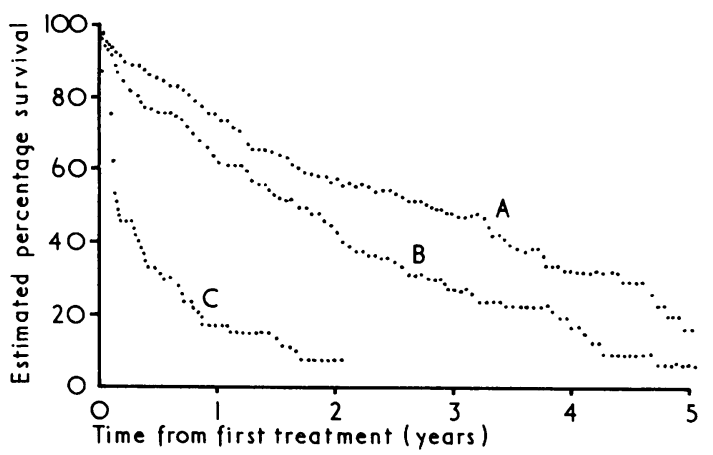

FIG. 2-Estimated percentage survival from the start of treatment of $\mathbf{2 7 6}$ patients suffering from myelomatosis divided into three groups according to the blood urea concentration at presentation. A, less than $40 \mathrm{mg} / 100 \mathrm{ml}$ (125 patients); median survival 33 months. B, $40-79 \mathrm{mg} / 100 \mathrm{ml}$ ( 96 patients); median survival 20 months. $\mathrm{C}, 80 \mathrm{mg} / 100 \mathrm{ml}$ or more (55 patients); median survival two months.

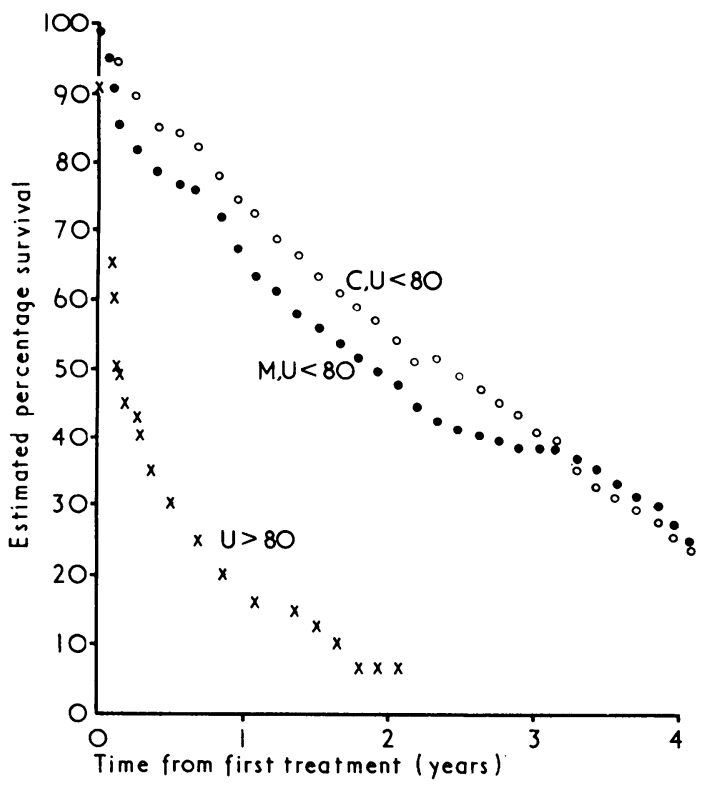

FIG. 3-Estimated percentage survival from the start of treatment of 274 patients suffering from myelomatosis divided into three groups according to treatment and urea concentration at presentation. U $>80$, blood urea $80 \mathrm{mg} / 100 \mathrm{ml}$ or more (55 patients); median survival two months : both $80 \mathrm{mg} / 100 \mathrm{ml}$ or more (55 patients); median survival two months : both
treatments. $\mathrm{C}, \mathrm{U}<80$, blood urea less than $80 \mathrm{mg} / 100 \mathrm{ml}$; treatment with cyclophosphamide. M,U $<80$, blood urea less than $80 \mathrm{mg} / 100 \mathrm{ml}$; treatment with melphalan.

\section{Discussion}

The main conclusion from the trial is that there is no significant difference between the effects of cyclophosphamide and melphalan, given by continuous oral administration, on the survival of patients suffering from myelomatosis. The other important finding is the progressive shortening of survival in groups of patients with progressively higher blood urea levels at presentation. This must be considered when different trials are compared. In some reported trials, previously treated as well as untreated patients were included, the number of patients was relatively small and the period of observation short. Survival times have been estimated from the onset of symptoms, the time of diagnosis, or the beginning of treatment. In this trial the median survival of 25 months from the start of treatment, in the 221 patients whose blood urea concentration at presentation was below $80 \mathrm{mg} / 100 \mathrm{ml}$, is not greatly different from other figures in published reports.

From two preliminary trials of melphalan therapy (Speed et al., 1964; Waldenström, 1964) it seemed possible that intermittent administration at high dosage was less likely to damage the bone marrow than continuous administration, but might also be less effective in controlling the disease. During the course of this trial the method of intermittent administration was reported to be more effective, and the addition of prednisone during each course of melphalan was found to give even better results (Bergsagel et al., 1967; Alexanian et al., 1969). The intake of patients was therefore stopped, and a second trial was begun in August 1968, in which the original schedule of continuous administration of melphalan was replaced by two schedules of intermittent administration, one with and one without the addition of prednisone. The original cyclophosphamide schedule was retained. The second trial is still in progress.

One of the benefits of a large-scale co-operative trial is the amount of new information which accrues about the disease under study. Professor J. R. Hobbs and his co-workers have already published a number of papers, largely derived from data on patients in the M.R.C. trials, on the abnormal proteins in the plasma and urine in myelomatosis. A detailed account of the findings in the first trial will be published shortly.

\section{Conclusions}

The median survival of 276 previously untreated but otherwise unselected patients suffering from myelomatosis was 18 months from the beginning of treatment with either cyclophosphamide or melphalan. The blood urea concentration at presentation was the most important single factor influencing the prognosis. There was no significant difference in survival between the groups treated with cyclophosphamide and melphalan.

The Working Party wishes to thank Dr. N. B. Ikoku and Miss M. Gilham, who collected most of the data, and Miss Gilham for the typescript. Messrs. Burroughs Wellcome and Company kindly supplied the tablets containing $0.25 \mathrm{mg}$ of melphalan which were prepared specially for the trial. The Working Party is grateful to the many colleagues who referred patients. The statistical analysis was carried out by Mr. R. Peto.

\section{References}

Alexanian, R., et al. (1969). Fournal of the American Medical Association, 208, 1680 .

Bergsagel, D. E., Griffith, K. M., Haut, A., and Stuckey, W. J. (1967). Advances in Cancer Research, 10, 311

Galton, D. A. G., and Peto, R. (1968). British fournal of Haematology, 15, 319.

Medical Research Council (1963). British Medical fournal, 1, 7.

Medical Research Council (1968). British Medical fournal, 1, 201. Speed, D. E., Galton, Fournal, 1, 1664.

Waldenström, J. (1964). British Medical fournal, 1, 859. 